\title{
Radiation fortification: a clinical scenario in India
}

\begin{abstract}
X-rays form the ionizing type of radiation which is used widely in medical and dental practices for detection of disease and other abnormalities, as well as to observe disease progression. Radiation is a double edged sword with therapeutic and detrimental effects. Dose reduction can be achieved by good decision-making, optimizing radiologic procedures and limitation of dose. Atomic Energy Regulatory Board AERB is the Indian regulatory board for protection against radiation
\end{abstract}

Keywords: radiation, dosimetry, protection, digital, justification, optimization, limitation

\author{
Volume 5 Issue 3 - 2018
}

Karthik Yadav D, Patil Bharati

'Department of Oral Medicine and Radiology, India

${ }^{2}$ The oxford dental college and research center, India

Correspondence: Karthik D Yadav, Department of Oral

Medicine and Radiology, 10th Milestone, Bommanahalli, Hosur Road, Bangalore-560 102, India, Tel +919902824646,

Email karthikyadavd@gmail.com

Received: February 04, 2018 | Published: June 14, 2018

\section{Introduction}

The transmission of energy through space and matter is termed as radiation. ${ }^{1} \mathrm{X}$-rays form the ionizing type of radiation which is used widely in medical and dental practices for detection of disease and other abnormalities, as well as to observe disease progression. However, the detrimental effects of radiation (deterministic and stochastic effects) cannot be neglected. ${ }^{1-3}$

Nowadays, even a small dental facility has an independent $\mathrm{x}$ ray unit for diagnosis, wherein the dentist by oneself processes and interprets the radiograph. Radiation is a double edged sword with therapeutic and detrimental effects. It is the clinician's decision in determining the need of the radiograph, wherein the diagnostic and therapeutic use outweighs the detrimental effects of radiation. Radiographs remain an indispensable diagnostic aid in dentistry. ${ }^{3}$

Digital imaging with photostimulable phosphor plates or solid state image receptors (i.e., CCD or CMOS receptors) present with the advantage of reduced radiation exposure by more than 50 percent without sacrificing diagnostic quality. ${ }^{1,4}$

Table I Radiation dose reduction by justification, optimization and limitation

\section{Discussion}

Radiation protection does not just imply protection of the patient alone but also the protection of the health personnel. AERB, Atomic Energy Regulatory Board (AERB) was established on November 15, 1983 which forms the Indian regulatory board for protection against radiation. The board ensures that the use of ionizing radiation and nuclear energy in India does not cause undue risk to health and surroundings. ${ }^{5}$ AERB provides AERB certification in order to procure $\mathrm{x}$ ray equipment from the medical equipment manufacturer. This certificate is provided for a period of 5 years. ${ }^{5}$ It would be very useful to be familiar with the AERB guidelines, as it will benefit the individual by dose reduction in the dental practice, wherein dental $\mathrm{x}$ - rays form a part of the ionizing radiation falling within the purview of the AERB . An individual dental practice is more focused towards the diagnostic process rather than for therapeutic procedures in india.

Dose reduction can be achieved by good decision-making, optimizing radiologic procedures and limitation of dose (Table 1). ${ }^{1}$ Decision making relies upon professional judgment which produces the maximum yield of information, directly benefiting the total health of the patient. ${ }^{1,2}$ The judgement vindicates the principle of justification.

Exposure justification The exposure should yield diagnostic information that will influence patient care.

Image receptors

Film: use the fastest speed available - currently F-speed. Film should be processed according to the manufacturer's instructions. A proper safe light should be used.

Digital: Charged Couple Device (CCD), Complementary metal-oxide semiconductor (CMOS) and storage phosphor receptors are acceptable.

Receptor holders Use to optimize alignment and minimize repeat exposures

Beam collimation

For intraoral radiographs limit beam diameter to 6 or $7 \mathrm{~cm}$ or smaller at the patient's face and preferably with rectangular collimation.

For all other radiographs, collimate the beam to the area under investigation.

For intraoral radiographs preferably use $60-70 \mathrm{kVp}$ to optimize contrast and reduce depth dose. Reduce

$\mathrm{kVp}, \mathrm{mA} \&$ exposure exposure time and/or $\mathrm{mA}$ when applicable.

time

Use machines with automatic exposure controls when available. If not, use technique charts or other appropriate means to minimize over- or under-exposures.

Image viewing

Radiographs should be viewed and evaluated on appropriate, quality assured viewing boxes (film) or monitors (digital) in a darkened environment.

Hand-held units

Where permitted, hand-held units should be stored in a locked facility when not in use and should always be used with a shielding ring and held close to the patient's face. 
Table continuded

CBCT

Quality Assurance

Operator protection

Education and

training
When indicated and when lower-dose techniques are not sufficient, use the smallest field of view sufficient to answer the clinical question and dose-minimizing procedures such as half-cycle exposures when appropriate.

Imaging data sets may need to be interpreted by an oral and maxillofacial radiologist.

Use leaded aprons and thyroid collars whenever possible.

Protocols should be developed and followed for assessing the integrity of the x-ray machine, film processor, digital image receptors, panoramic cassettes, and darkroom.

Operators should stand out of the primary beam, at least $2 \mathrm{~m}$ away from the source, and behind a protective barrier whenever possible.

An important method for keeping patient exposure as low as reasonably achievable (ALARA) is the appropriate prescription of radiographs. ${ }^{4}$ This in fact includes the radiological exposure of the patient which is given more importance than the history and clinical examination of the patient, which might be sufficient enough to provide treatment for the patient. Hence, the expectation that the radiograph will provide a diagnostic yield affecting patient care should be the sole reason for the radiograph. All reasonable means should be used to reduce radiation exposures, without compromising diagnosis, when radiographs are made. ${ }^{3}$

The stabilization of patient head before the exposure decreases blurring and cone-cutting of the image. All radiation exposure must be based on the principle ALARA (as low as reasonably achievable). Mean exposure at skin entrance for single periapical film is $217 \mathrm{mR}$ and gonad dose will be $1 / 10,000$ of total beam exposure $(0.02 \mathrm{mR})$. Lead aprons reduce $98 \%$ of scattered radiation. ${ }^{2,4,6,7}$ Thyroid collar attenuates $92 \%$ of scattered radiation. Though it is not mandatory it is good to use thyroid collar and lead apron (Figure 1). ${ }^{2}$

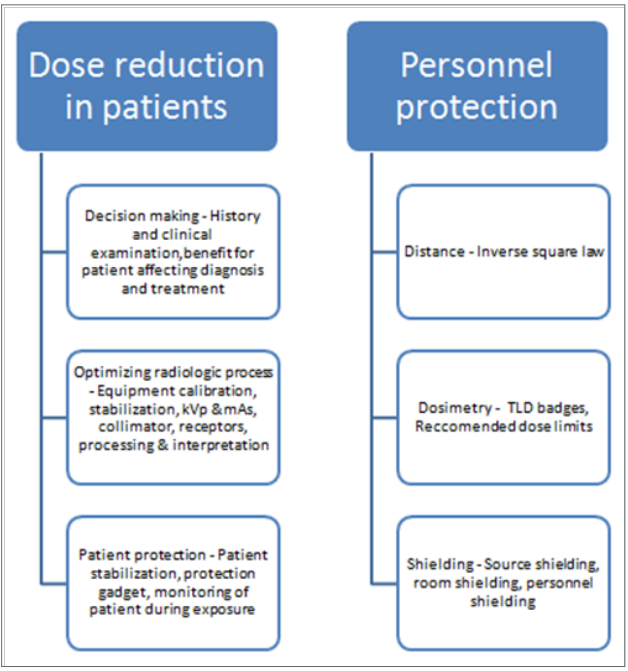

Figure I Dose reduction and patient and health personnel protection.

Film holders should be used to avoid unnecessary exposure to patient's fingers. Radiologic procedures should be avoided during pregnancy and should only be the last option of choice. ${ }^{8}$ In a working environment there are two sources of radiation, the X-ray tube forms the true primary source of radiation but the direct exposure of the healthcare workers to the primary beam is scarce as the healthcare personnel are aware of the position distance rule with the operator standing at least 6 feet from patient at an angle of 90 to $135^{\circ}$ to the central ray of X-ray beam. ${ }^{1,2,5,8}$

The inverse square law helps to reduce X-ray intensity; however most of the scattered radiation is captivated by the patient's head. A distance of at least 2 meter away from the patient, X-ray tube and primary beam during exposure, has been advised in mobile radiography. ${ }^{1,2,8}$ In digital radiography the optimal exposure time for photostimulable phosphor plates or solid state image receptors (i.e., CCD or CMOS receptors) is approximately half that needed for conventional film and those digital images need to be modified by adjusting the contrast and brightness to optimize the visibility of the region of interest. Although digital radiography offers a significant dose reduction, the number of retakes (essentially due to bad positioning of the bulky CCD with its' encumbering wire) may result in increased dose for the patient. Furthermore, due to smaller sensor sizes, more than one exposure may be required to cover the anatomical area imaged using a single conventional film. Problems with positioning sensors have been reported as leading to high reject rate. ${ }^{4,6}$

Shielding indicates that certain material (concrete, lead) will attenuate radiation when placed between source and the operator. Shielding take account of X-ray tube shielding, room shielding and personnel shielding. ${ }^{1,8}$ AERB recommends maximum allowable leakage from tube housing not greater than $1 \mathrm{mGy} / \mathrm{hr} / 100 \mathrm{~cm}^{2}$. Room and personnel shielding-according to AERB guidelines: (i) Room area housing a X-ray unit in dentistry should not be less than $12 \mathrm{~m}^{2}$; (ii) Walls of X-ray room on which primary beam falls should not be less than $35 \mathrm{~cm}$ thick brick and the walls on which scattered X-ray falls should not be less than $23 \mathrm{~cm}$ thick brick; (iii) $1.5 \mathrm{~mm}$ lead shielding in front of the doors and windows of X-ray room; (iv) unshielded openings in an X-ray room should be located above a height of $2 \mathrm{~m}$ from ground level outside the X-ray room; (v) rooms should have a provision for direct viewing and oral communication facilities between the operator and the patient; (vi) protective barrier between the operator and patient should have a minimum lead equivalence of $1.5 \mathrm{~mm}$ and protective apron and gloves should have minimum lead equivalence of $0.25 \mathrm{~mm}$. One millimeter of lead thickness attenuates $99 \%$ beam at $75 \mathrm{kVp} .5$

Radiation dosimeters are devices used to detect and measure radiation. The purpose of radiation monitoring is to ensure that the dose limits are not exceeded and protection measures are doing well. There are several methods of detecting radiation, based on physical and chemical effects like ionization, photographic effect, luminescence and scintillation. ${ }^{2,8}$ 
Thermoluminescent monitoring badges (TLD) are commonly used in India. Thermoluminescene is the property of certain materials to emit light when they are stimulated by heat. The amount of light emitted is proportional to the radiation dose. Materials such as lithium fluoride, lithium borate, calcium fluoride and calcium sulfate have been used to make TLDs. In India M/s. Renentech Laboratories Pvt. Ltd (Mumbai), M/s. Avanttec laboratories Pvt. Ltd (Chennai), are accredited to provide personnel monitoring devices at a minimal cost of 800 rupees while M/s Utra-Tech Laboratories Pvt. Ltd (Bhilai), is in the process of accredition to Bhabha Atomic Research Centre. ${ }^{1,5}$

During radiography the dosimeter is worn at one of 2 regions-on the trunk of the body at the level of the waist on the anterior side of the individual or on the upper chest region at the level of the collar area on the anterior surface of the individual. Badge should be sent once for the dose measurement in every 3 months. Future technology is under development that utilizes compact personal electronic monitoring devices that wirelessly connect to a base station. So all the staff involved in a complex imaging procedure can monitor their doses in real time and use this information to modify their practice. ${ }^{2,9}$

\section{Conclusion}

AERB is the Indian regulatory board for protection against radiation, the guidelines formed by them form an important curriculum in the formation and maintenance of the clinics. Hence, one should go through the guidelines before setting up a clinical practice.

\section{Acknowledgements}

None.

\section{Conflict of interest}

The author declares that there is no conflict of interest.

\section{References}

1. White SC, Pharoah MJ. Oral Radiology, Principles and Interpretation. $6^{\text {th }}$ ed.

2. BN Praveen, AR Shubhasini, R Bhanushree, et al. Radiation in Dental Practice: Awareness, Protection and Recommendations. J Contemp Dent Pract. 2013;14(1):143-148.

3. The 2007 Recommendations of the International Commission on Radiological Protection. International Commission on Radiological Protection. 2007.

4. European guidelines on radiation protection in dental radiology. Radiation protection.

5. http://www.aerb.gov.in/index.php/english/acts-regulations

6. Richards AG. Roentgen ray doses in dental radiography. $J$ Am Dent Assoc. 1958;56(3):351-368.

7. http://www.fdiworlddental.org//2-fdi_ps radiation_safety_in_dentistry_ approved_gab_2014.pdf

8. Karjodkar F. Textbook of Dental and Maxillofacial Radiology. 2nd edition. 